\title{
An unusual cause of pulmonary hypertension and right heart failure
}

\author{
S Orme, J C E Underwood, E McCloskey, T J Hendra
}

A 50-year-old woman presented with a 6-month history of dyspnoea and ankle oedema in the absence of paroxysmal nocturnal dyspnoea or orthopnoea. Two days prior to admission she became more dyspnoeic and was unable to attend to her activities of daily living. There was no history of cough or fever. At age 2 years she had been diagnosed as having fibrodysplasia ossificans progressiva which had resulted in kyphoscoliosis and fixed flexion deformities at her knees, elbows, and wrists. She had received treatment with periodic cyclical etidronate since age 25 years. At age 48 years formal respiratory function tests had confirmed a diagnosis of a restrictive lung defect with an $\mathrm{FEV}_{1}$ of 0.741 (27\% of predicted) and an FVC of 0.961 (29\% of predicted) the $\mathrm{FEV}_{1} / \mathrm{FVC}$ was $77 \%$ ( $94 \%$ of predicted).

On examination she was apyrexial. She was tachypnoeic at rest with a respiratory rate of 40 breaths/min and was centrally cyanosed. She was noted to have short great toes and the fixed flexion deformities were documented. She was in sinus rhythm at a rate of 100 beats $/ \mathrm{min}$ and her blood pressure was $137 / 87 \mathrm{mmHg}$. The jugular venous pressure was raised to the angle of the jaw with marked $\mathrm{V}$ waves. She had a right ventricular heave, a soft systolic murmur audible at her left sternal edge and bilateral pitting oedema to her knees. There was restricted expansion of the chest wall with globally reduced air entry in the absence of wheeze or focal crepitations.

Her full blood count revealed a haemoglobin of $17.6 \mathrm{~g} / \mathrm{dl}$ with a packed cell volume of 0.593 (normal range $0.3-0.5$ ), a white cell count of $6.5 \times 10^{9} / 1$, with a normal differential cell count and a platelet count of $178 \times 10^{9} / 1$. Serum biochemistry was normal other than a raised bicarbonate $32 \mathrm{mmol} / \mathrm{l}$. She was hypoxic on pulse oximetry with a saturation of $72 \%$ on air. Formal arterial blood gases were not performed because of the concerns about arterial puncture in this condition. Her electrocardiogram (ECG) and chest X-ray are shown in figures 1 and 2, respectively. Despite intensive treatment she had an asystolic arrest and died.

At post-mortem she was found to have gross right ventricular hypertrophy due to pulmonary hypertension. The latter was thought to be a consequence of chronic hypoxia secondary to a restrictive lung defect associated with her muscle disease.

Royal Hallamshire Hospital, Glossop Road, Sheffield S10 2RA, UK Department of Geriatric Medicine S Orme T J Hendra Department of Pathology J C E Underwood Centre for Metabolic Bone Diseases

E McCloskey

Correspondence to Dr Hendra

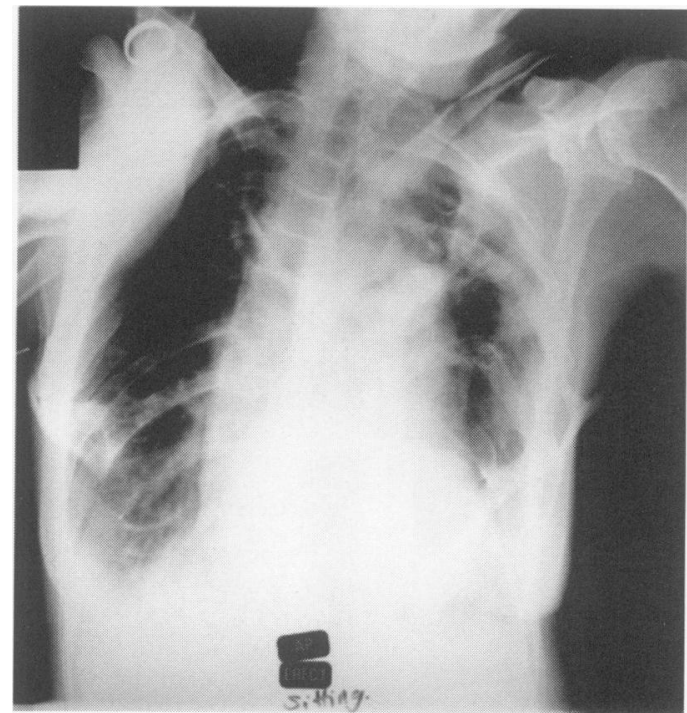

Figure 2 Chest X-ray

1 Describe the features shown in the ECG (figure 1).

2 Describe three obvious radiological features on the chest X-ray (figure 2).

\section{Questions}




\section{Answers}

QUESTION 1

The ECG shows signs consistent with right ventricular hypertrophy with strain. There is a dominant $R$ wave in V1 with right axis deviation. There are peaked $P$ waves and $T$ wave inversion in leads V1-V4.

A number of conditions can produce this ECG appearance and these are listed in box 1.

\section{Causes of cor pulmonale and right ventricular strain on ECG}

- severe asthma

- chronic obstructive airways disease

- multiple pulmonary emboli

- primary pulmonary hypertension

- pulmonary fibrosis

- obesity-hypoventilation syndrome

- neuromuscular disorders

- disorders of the thoracic cage

\section{Box 1}

QUESTION 2

The chest $\mathrm{X}$-ray shows extensive soft tissue calcification. There are bilateral interstitial changes in the lung fields. The flexion deformities at the wrist and elbow can be appreciated from the position of the patient's limbs.

\section{Discussion}

Fibrodysplasia ossificans progressiva (myositis ossificans progressiva), is an autosomal dominant disorder of variable penetrance but due to low reproductive fitness the majority of cases occur sporadically. It causes progressive calcification within striated muscle and soft tissue. ${ }^{12}$ The ossification within muscle results in fixed deformities and restricted joint movement and most patients are confined to a wheelchair by the third decade. The musculature of the neck and back are commonly involved. In the majority of cases there are other associated congenital abnormalities including mental retardation, deafness and failure of development of the thumbs. The characteristic associated

1 Connor JM, Skirton H, Lunt PW. A three generation family with fibrodysplasia ossificans progressiva. $₹ \mathrm{Med}$ Genet with fibrodysplasi

2 Kaplan FS, McCluskey W, Hahn G, Tabas JA, Muenke M, Zasloff MA. Genetic transmission of fibrodysplasia ossificans progressiva. Report of a family. $\mathcal{f}$ Bone foint Surg (Am) 1993;75:1214-20.

3 Connor JM, Evans DA. Fibrodysplasia ossificans progressiva. The clinical features and natural history of 34 patients. f Bone foint Surg $(B r) 1982 ; 64: 76-83$.

4 Smith R, Athanasou NA, Vipond SE. Fibrodysplasis (myositis) ossificans progressiva: clinicopathological features and natural history. $O f M e d$ 1996;89:445-6.

\section{Summary points}

myositis ossificans progressiva is an autosoma dominant condition with variable penetrance

- patients with this condition have

characteristically short great toes

- there is progressive calcification of muscle and soft tissues resulting in fixed deformities

- avoidance of trauma is the mainstay of treatment

Box 2

abnormality is short great toes, which is often used as an aid to diagnosis. Exostoses are frequent and developmental fusion of cervical vertebrae may lead to diagnostic confusion with Klippel-Feil syndrome or Still's disease. ${ }^{34}$ The condition can be exacerbated by trauma and dental therapy. There is a risk of calcification associated with venous puncture and intramuscular injection and these are best avoided if possible. ${ }^{3}$

The disease process is relentlessly progressive and treatment with a variety of agents including corticosteroids, non-steroidal inflammatory agents, radiotherapy, warfarin, and EDTA has proved to be unsatisfactory. Periodic therapy with etidronate sodium has been advocated, ${ }^{5}$ however, although useful in acute exacerbations of pain and swelling it may not influence joint involvement and disability in the long term. ${ }^{6}$ Clinical improvement in motor function has also been demonstrated with intravenous dichoromethylenebisphosphonic acid in a series of three patients. ${ }^{7}$ Avoidance of unnecessary trauma remains the mainstay of therapy.

Although the diaphragm, heart and smooth muscles are characteristically spared, calcification of the intercostal muscles results in a restrictive ventilatory defect, chronic hypoventilation and hypoxia leading to pulmonary hypertension and right-sided heart failure. The cause of death is usually respiratory failure precipitated by pulmonary infection.

\section{Final diagnosis}

Pulmonary hypertension in a patient with myositis ossificans progressiva.

Keywords: fibrodysplasia ossificans progressiva; ventricular hypertrophy

5 Bruni L, Giammaria P, Tozzi MC, Camparcola D, Scopinaro F, Imperato C. Fibrodysplasia ossificans progressiva. An 11 year old boy treated with a bisphosphonate. Acta Paediatr Scand 1990;79:994-8.

$6 \mathrm{Oz} \mathrm{BB}$, Boneh A. Myositis ossificans progressiva: a 10 year follow-up on a patient treated with etidronate disodium. Acta Paediatr 1994;83:1332-4.

7 Alpigiani MG, Puleo MG, Callegarini L et al. L'acido diclorometilenbifosfonico nella terapia della miosite ossificante progressiva. [Dichloromethylenebisphosphoric acid therapy for myositis ossificans progressiva.]Min Pediatr 1996;48:159-63. 